\title{
Ultraviolet vision in European owlflies (Neuroptera: Ascalaphidae): a critical review
}

\author{
KARL KRAL \\ Institut für Zoologie, Karl-Franzens-Universität Graz, A-8010 Graz, Austria; e-mail: karl.kral@kfunigraz.ac.at
}

Key words. Owlfly, Ascalaphus, Neuroptera, insect vision, ultraviolet sensitivity, visual acuity, visual behaviour, visual pigment

\begin{abstract}
This review critically examines the ecological costs and benefits of ultraviolet vision in European owlflies. On the one hand it permits the accurate pursuit of flying prey, but on the other, it limits hunting to sunny periods. First the physics of detecting short wave radiation are presented. Then the advantages and disadvantages of the optical specializations necessary for UV vision are discussed. Finally the question of why several visual pigments are involved in UV vision is addressed.
\end{abstract}

\section{UV vision in predatory European owlflies}

The European owlflies, like Ascalaphus macaronius, A. libelluloides, A. longicornis and Libelloides coccajus are rapidly-flying neuropteran insects, which hunt in open country for flying insects. These owlflies are only adapted for daytime activity. They have large double eyes, which structurally correspond to optical refracting superposition eyes (Ast, 1920; Gogala \& Michieli, 1965; Schneider et al., 1978; for review, see Nilsson, 1989).

In the late 1960's Matija Gogala, of the University of Ljubljana, combined the results of behavioural observations in the field with electroretinogram recordings on Ascalaphus macaronius. His electrophysiological studies revealed that the dorsofrontal part of the eye is sensitive to UV light and he concluded that this might be important in hunting prey (Gogala, 1967). His finding that the eyes of owlflies are sensitive to UV light is interesting and initiated a series of studies that led to a better understanding of UV vision not only in insects, but also in other animals (Gogala et al., 1970; Hamdorf et al., 1971; Schwemer et al., 1971; Paulsen \& Schwemer, 1972; Hamdorf \& Gogala, 1973; for review, see Hamdorf, 1979).

Recent studies on Ascalaphus by Gribakin et al. (1995) indicate that the large photoreceptor cells R1-R6 in the ventrolateral part of the eye of Ascalaphus macaronius, are maximally sensitive in the green region of the spectrum $\left(\lambda_{\max }=520 \mathrm{~nm}\right)$, whereas the small photoreceptor cells $\mathrm{R} 7$ and $\mathrm{R} 8$ are maximally sensitive in the ultraviolet region $\left(\lambda_{\max }=343 \mathrm{~nm}\right)$. The compound eyes of other neuropteran species (e.g. Chrysoperla carnea: Kral \& Stelzl, 1998; Mantispa styriaca: Mayer \& Kral, 1993) are similarly sensitive. In contrast, the large photoreceptor cells R1-R6 in the dorsofrontal part of the eye of Ascalaphus, are maximally sensitive in the UV region of the spectrum $\left(\lambda_{\max }=330 \mathrm{~nm}\right)$ (Gribakin et al., 1995). Analogous with the situation in other superposition eyes, the small photoreceptor cell $\mathrm{R} 8$ may be sensitive in the blue-green region of the spectrum (Stušek et al., 2000). The proximal position of the rhabdomere of R8 relative to the rhabdomere of R7 means that the former receives only the longer wavelengths, since the short wavelengths are absorbed by the latter. However, intracellular electrophysiological recordings or microspectrophotometry on these tiny photoreceptors have not been done so their spectral sensitivity is unknown (P. Stušek, personal communication).

\section{Advantages of UV vision}

What are the advantages of using UV light for locating and capturing prey seen against the sky? The utilization of UV light may limit the diffraction of the light providing the stimulus. This is critical, since it is the diffraction of the incident light that determines the resolving power of an eye. Here, resolving power is the ability to detect a small object, for instance prey, even at great distances. The stimulation of an ommatidium by daylight creates a diffraction pattern on the rhabdom layer, which is known as the Airy disc. The Airy disc consists of a central spot of high intensity, surrounded by rings of minima and maxima of sharply decreasing intensity. The shorter the wavelength of the stimulating light and the wider the lens aperture $(D)$, the smaller and sharper the Airy disc and the greater the sharpness of the image.

The half-width of the Airy disc, i.e. the width of the brightness distribution at half maximum intensity (see e.g. Land, 1997) can be calculated at a given ratio of $\lambda / D$ radians, where $\lambda$ denotes the wavelength of the received light and $D$ represents the facet diameter. This is possible because Ascalaphus has a conventional ommatidial structure, i.e. a 1:1 relationship between lenses and rhabdoms. In the dorsofrontal part of the eye of Ascalaphus where UV light $\left(\lambda_{\max }=330 \mathrm{~nm}\right)$ is perceived and $D=31 \mu \mathrm{m}$ which results in a half-width of $0.6^{\circ}$. In contrast, in the ventrolateral part of the eye, $\lambda$ is the wavelength $(520 \mathrm{~nm})$ of green light and $D=25 \mu \mathrm{m}$, giving a value of $1.2^{\circ}$. Thus, the width of the Airy disc in the dorsofrontal part of the eye is half that in the ventrolateral region. This means that the images on the rhabdom layer should be much sharper in the dorsofrontal part of the eye.

What is the significance of these angular values? They not only indicate image sharpness, but also give a rough 
estimate of the resolving power of the eye. In conjunction with anatomical data, the rhabdom acceptance angle $\Delta \rho$, which is a measure of the resolving power, can (also in superposition eyes) be estimated by means of the formula $\Delta \rho \approx\left[\sqrt{ }(\lambda / D)^{2}+(d / f)^{2}\right]$, where $d$ is the diameter of the stimulated rhabdom and $f$ is the focal length of the lens system (M. Land, personal communication). In the dorsofrontal part of the eye, $d$ is approximately $1-10 \mathrm{~mm}$ (R1-R6) for the light-adapted state, depending on the intensity of the light. In the ventrolateral part of the eye, $d$ has a value of 7-10 $\mathrm{mm}$. There are consistent optically determined data on the focal length $f$, however, estimates may be made based on the principles of superposition optics, where the focal length $f$ is usually about half the radius of curvature of the eye (Land, 1997; M. Land, personal communication). The estimates of the focal length $f$ based on histological data obtained from longitudinal sections through eyes (Schneider et al., 1978) are $635 \mu \mathrm{m}$ and $350 \mu \mathrm{m}$ for the dorsofrontal and ventrolateral parts of the eye, respectively. For the dorsofrontal part of the eye, where UV light $\left(\lambda_{\max }=330 \mathrm{~nm}\right)$ is received, this results in a very small range of rhabdom acceptance angles $\Delta \rho$, between $0.6-1.1^{\circ}$. In contrast, in the ventrolateral part of the eye the $\Delta \rho$ for green light $\left(\lambda_{\max }=520 \mathrm{~nm}\right)$ ranges between $1.6-2.0^{\circ}$. However, these angular values need to be verified using optical and electrophysiological measurements.

What are the implications of the small rhabdom acceptance angles, $\Delta \rho$, of $0.6-1.1^{\circ}$ for the resolving power of the dorsofrontal part of the eye and prey-capture by $A s c a-$ laphus? This is revealed by observing their hunting behaviour. If the hunting flights of Ascalaphus are observed in the field on a sunny summer's day, ideally in the boundary between meadow and blue sky looking away from the sun, it is immediately noticeable that the flights are very similar to those of a dragonfly. Once the dorsofrontal part of the eye detects a potential prey, such as a fly, Ascalaphus darts toward the prey at very high speed and seizes it from below. The distances at which Ascalaphus seems to detect its prey range up to $1 \mathrm{~m}$ and may be greater in some instances. In his field studies, Stušek observed that Ascalaphus can detect flying insects at distances of even a few meters (personal communication). In cases where the prey size ranges between $5-10 \mathrm{~mm}$ and is $1 \mathrm{~m}$ away the visual angle is no greater than about $0.3-0.6^{\circ}$. Rhabdom acceptance angles $\Delta \rho$ of $0.6-1.1^{\circ}$ in the dorsofrontal part of the eye would indicate that the pursuit of prey may be triggered by a brief half-maximum to maximum decrease in intensity of the UV portion $\left(\lambda_{\max }=330 \mathrm{~nm}\right.$ ) of daylight in rhabdoms (R1-R6). Due to the lack of experimental data, it is currently impossible to estimate how the sensory excitation level may be influenced by the blue background illumination, which depends on the size of the superposition aperture.

In summary, it can be concluded that, in conjunction with an enlarged facet diameter $D$ and elongated ommatidia (i.e. a greater radius of curvature of the eye), the reduction in the rhabdom acceptance angle $\Delta \rho$ of UV light to values of between $0.6-1.1^{\circ}$ enables Ascalaphus to detect small prey (i.e. $5 \mathrm{~mm}$ in size) at distances well over $1 \mathrm{~m}$.

There is a further possible advantage of UV-vision for Ascalaphus. This has already been discussed by Gogala (1967), based on his behavioural observations on the hunting territory of Ascalaphus viewed through UV filters and UV-blocking filters. In the ultraviolet region of the spectrum he found the sky to appear brighter and more uniform (homogeneous). Furthermore, the considerable dispersion of short wavelength light resulted in a quite hazy view compared to long wavelength light. Ascalaphus may greatly benefit from those background properties when viewing flying insects against the sky (see also Mazokhin-Porshnyakov, 1959).

\section{How can a high resolution be achieved when the proportion of light that is UV is so small?}

Is it not risky for the visual component of the preycapturing system to be restricted to such a very small portion of the total energy available (Henderson \& Hodgkiss, 1963)? In the case of the dorsofrontal part of the eye of Ascalaphus, this limitation is particularly extreme. This seems to be reflected in the animal's hunting behaviour. They only fly on sunny days with clear blue skies, but not if the sun is obscured, and certainly not if the sky is overcast. As soon as a cloud covers the sun, they land and wait until the sun is unobscured again (see also Gogala, 1967).

In the UV-sensitive dorsofrontal part of the eye of Ascalaphus, there is also an iris mechanism, which serves to maintain the UV-absorbing rhodopsin at a high concentration level (Schneider et al, 1978; see also Stušek \& Hamdorf, 1999; Stušek et al., 2000). Kirschfeld and Wenk (1976) showed that male simuliid flies may employ a similar "iris mechanism", though in a different behavioural context, to maintain a high rhodopsin concentration in the UV photoreceptors. In Ascalaphus, this specialization was identified by Schneider et al. (1978) by means of microspectrophotometry using sections of fresh and deepfrozen eyes. The pupil is composed of primary pigment cells containing yellow granules, which function as an iris with respect to UV and violet light, while allowing light of longer wavelengths $(\lambda=500-700 \mathrm{~nm})$ to pass. The maximum absorption of these pigment granules lies approximately at $\lambda=410 \mathrm{~nm}$, which is midway between the values for UV-rhodopsin $\left(\lambda_{\max }=330 \mathrm{~nm}\right)$ and the related metarhodopsin $\left(\lambda_{\max }=475 \mathrm{~nm}\right)$. Thus, the aperture is markedly greater for light of longer wavelengths, which is exclusively absorbed by metarhodopsin, than it is for UV light. This means that, in accordance with superposition optics, light from the blue region of the spectrum is captured by several dioptric apparatuses and superposed on the rhabdoms. For UV light the situation is different, as only the incident light rays that are parallel to the optical axis will be received by the receptors. This greatly increases the intensity of the rhodopsin-regenerating blue light in the rhabdoms, which then causes all metarhodopsin molecules to immediately regenerate rhodopsin. Consequently, under natural lighting conditions with respect to the blue range of the spectrum, the photo- 
chemical equilibrium between rhodopsin and metarhodopsin is almost completely on the side of the intact rhodopsin. Thus, UV-sensitivity is constantly maintained at a high level (see Hamdorf, 1979). This mechanism may compensate for the fact that UV makes up a comparatively small proportion of daylight. In addition, a special mechanism of the photo-transductional cascade seems also to be responsible for the rapid regeneration of UVsensitive rhodopsin (Stušek et al., 2000; Bentrop et al., 2001).

It is possible that the small photoreceptor cell R7 may be involved in this pupil mechanism (Stušek et al., 2000; P. Stušek, personal communication). R7 extends up to the tip of the crystalline cone, where it could easily absorb its portion of light. Nevertheless, because of its tiny diameter, R7 probably does not contribute much to vision or prey detection against the sky, but may serve a different function. The function of the other small photoreceptor cell, R8, is even more obscure, since it appears to be rudimentary.

In addition, the superposition eyes of Ascalaphus and of other Neuroptera, such as mantispids, possess special anatomical characteristics, which increase the efficiency by which light of particular wavelengths can be exploited (Schneider et al., 1978; Eggenreich \& Kral, 1990; Kral et al., 1990; Stušek \& Hamdorf, 1999; Stušek et al., 2000). This is particularly so in the dorsofrontal part of the eye of Ascalaphus. In this area the comparatively small acceptance angle plus a - presumably - short integration time may result in the capture of few photons. To compensate for this special characteristics have evolved. These include protuberances on the cornea, which might increase the absorption of the incident light (although the protuberances appear to be smaller than the wavelengths involved) and a dioptric apparatus of high optical quality (Schneider et al., 1978). It might well be that the whole dioptric system improves UV vision.

\section{Specialization of the visual pigments used in UV vision}

In Ascalaphus and some other insects, the dorsal part of the eye contains UV-sensitive photoreceptor cells used exclusively to detect small moving objects against the sky. These photoreceptor cells contain the UV-sensitive visual pigment rhodopsin (Paulsen \& Schwemer, 1972; Kirschfeld \& Vogt, 1986; Vogt, 1989; see also Labhart \& Nilsson, 1995). Rhodopsin consists of the protein "opsin" and the vitamin A aldehyde "retinal", the so-called "chromophore", responsible for phototransduction. It is interesting that in this animal, in parts of the eye not involved in detecting small objects, xanthopsin (with the chromophore 3-hydroxyretinal) rather than rhodopsin is used as the UV-absorbing visual pigment (Paulsen \& Schwemer, 1972; Vogt, 1989). Xanthopsin is also found in butterflies (e.g. Arikawa et al., 1999). How can we account for the presence of two different UV-absorbing visual pigments in the same optical system? Electrophysiological recordings from UV-sensitive photoreceptors in Ascalaphus indicate that where retinal is used the maximum sensitivity to UV light is shifted even further into the shortwavelength region compared to where 3-hydroxyretinal is the chromophore (Gribakin et al., 1995). As a result, the resolving power of the dorsal part of the eye may be improved by a further few percent (see wavelength theory, cited above; see also Kirschfeld \& Vogt, 1986; Vogt, 1989; Seki \& Vogt, 1998).

ACKNOWLEDGEMENTS. Thanks to Mary Ansell for translating the first draft of the manuscript into English. I am grateful to Drs. Peter Stušek, Michael Land, Dan-E. Nilsson and an anonymous reviewer for many valuable comments on the manuscript. This work was supported by research grants from the Austrian Science Foundation (Grant No. P14697-Bio to K.K.)

\section{REFERENCES}

Arikawa K., Mizuno S., Scholten D.G.W., Kinoshita M., Seki T., Kitamoto J. \& Stavenga D.G. 1999: An ultraviolet absorbing pigment causes a narrow-band violet receptor and a single-peaked green receptor in the eye of the butterfly Papilio. Vision Res. 39: 1-8.

Ast F. 1920: Über den feineren Bau der Facettenaugen bei Neuropteren. Zool. Jb. 41: 411-458.

Bentrop J., Schillo M., Gerdon G., Drašlar K. \& Paulsen R. 2001: UV-light-dependent binding of a visual arrestin 1 isoform to photoreceptor membranes in a neuropteran (Ascalaphus) compound eye. FEBS Lett. 493: 112-116.

EgGenReich U. \& Kral K. 1990: External design and field of view of the compound eyes in a raptorial neuropteran insect, Mantispa styriaca. J. Exp. Biol. 148: 353-365.

Gogala M. 1967: Die spektrale Empfindlichkeit der Doppelaugen von Ascalaphus macaronius SCOP. (Neuroptera: Ascalaphidae). Z. Vergl. Physiol. 57: 232-243.

Gogala M. \& Michieli Š. 1965: Das Komplexauge von Ascalaphus, ein spezialisiertes Sinnesorgan für kurzwelliges Licht. Naturwissenschaften 52: 217-218.

Gogala M., Hamdorf K. \& Schwemer J. 1970: UV-Sehfarbstoff bei Insekten. Z. Vergl. Physiol. 70: 410-413.

Gribakin F., Alekseyev E., Shukolyukov S. \& Gogala M. 1995: Unconventional ultraviolet sensitivity spectra of Ascalaphus (Insecta, Neuroptera). J. Comp. Physiol. 177: 201-206.

HAMDORF K. 1979: The physiology of invertebrate visual pigments. In Autrum H. et al. (eds): Handbook of Sensory Physiology, Vol. VII/6A, Springer-Verlag, Berlin, Heidelberg, New York, pp. 145-224.

HAMDORF K. \& Gogala M. 1973: Photoregeneration und Bereichseinstellung beim UV-Rezeptor. J. Comp. Physiol. 86: 231-245.

HAMdorf K., Schwemer J. \& Gogala M. 1971: Insect visual pigment sensitive to ultraviolet light. Nature (Lond.) 231: 458-459.

Henderson S. T. \& Hodgkiss D. 1963: The spectral energy distribution of daylight. Br. J. Appl. Phys. 14: 125-131.

KIRSCHFELD K. \& WENK P. 1976: The dorsal compound eye of simuliid flies: An eye specialized for the detection of small, rapidly moving objects. Z. Naturforsch. 31: 764-765.

KIRSCHFELD K. \& VOGT K. 1986: Does retinal serve a sensitizing function in insect photoreceptors? Vision Res. 26: 1771-1777.

KRAL K. \& STELzL M. 1998: Daily visual sensitivity pattern in the green lacewing Chrysoperla carnea (Neuroptera: Chrysopidae). Eur. J. Entomol. 95: 327-333.

Kral K., Herbst K. \& Pabst M.A. 1990: The compound eye of Mantispa styriaca (Neuroptera: Planipennia). Zool. Jb. Physiol. 94: 333-343. 
LABHART T. \& NiLsSON D.-E. 1995: The dorsal eye of the dragonfly Sympetrum: specializations for prey detection against the blue sky. J. Comp. Physiol. A 176: 437-453.

Land M.F. 1997: Visual acuity in insects. Annu. Rev. Entomol. 42: $147-177$.

MAYeR H. \& Kral K. 1993: Electrophysiological and optical studies of the spectral sensitivity of Mantispa styriaca (Neuroptera: Planipennia). Mitt. Dt. Ges. Allgem. Angew. Entomol. 8: 709-713.

MazokHIN-PoRshnYakov G.A. 1959: Colorimetric study of colour vision in the dragonfly. Biofizika 4: 427-436.

NiLsson D.-E. 1989: Optics and evolution of the compound eye. In Stavenga D.G. \& Hardie R.C. (eds): Facets of Vision Springer-Verlag, Berlin, Heidelberg, New York, pp. 30-73.

PAUlsen R. \& SChWeMer J. 1972: Studies on the insect visual pigment sensitive to ultraviolet light: retinal as the chromophore group. Biochim. Biophys. Acta 283: 520-529.

Schneider L., Gogala M., Drašlar K., Langer H. \& Schlecht P. 1978: Feinstruktur und Schirmpigment-Eigenschaften der
Ommatidien des Doppelauges von Ascalaphus (Insecta: Neuroptera) Cytobiology 16: 274-307.

Schwemer J., Gogala M. \& Hamdorf K. 1971: Der UVSehfarbstoff der Insekten: Photochemie in vitro und in vivo. Z. Vergl. Physiol. 75: 174-188.

SEKI T. \& VoGT K. 1998: Evolutionary aspects of the diversity of visual pigment chromophores in the class Insecta. Comp. Biochem. Physiol. B 119: 53-64.

Stušek P. \& HAMdorF K. 1999: Properties of pupil mechanisms in owl-fly Ascalaphus macaronius (Neuroptera). J. Comp. Physiol. A 184: 99-106.

Stušek P., Drašlar K., Belušič G. \& Zupančič G. 2000: Adaptation mechanisms in insect eyes. Acta Biol. Sloven. 43: 41-70.

VOGT K. 1989: Distribution of insect visual chromophores: functional and phylogenetic aspects. In Stavenga D.G. \& Hardie R.C. (eds): Facets of Vision. Springer-Verlag, Berlin, Heidelberg, New York, pp. 134-151.

Received April 12, 2001; revised December 12, 2001; accepted January 17, 2002 